\title{
Energetic state parameters measurements of LM 2500 naval gas turbine for modeling and simulation purposes
}

This article presents examples of results of energetic state parameters measurements of LM 2500 naval gas turbines operated by the Polish Navy. Currently in operation there are four LM 2500-type engines. In the near future, another LM 2500 engine will commence operations, along with a project $661 \mathrm{M}$ patrol ship. The energetic state parameters measurements covers the engine start-up process, their operation in idle mode and within the whole range of load variations, as well as stoppage of engine process. The article presents examples of characteristics specific to the above processes, determined based on the results of studies of this kind of engines. The results of these studies will be used to verify the modeling and simulation results of the internal energy processes occurring in this kind of engine.

Key words: a naval gas turbine, operating characteristic of naval gas turbine, LM 2500, diagnostics, energy research

\section{Introduction}

In practical operation of naval power plants, including also naval propulsion systems with naval gas turbines, there is a need for analyzing them and comparing various solutions as well as for evaluating their technical condition [3, $5,7-9,16]$. At the present time, the operation of engines and broad technical equipment is aimed at increasing their reliability, higher performance and energy efficiency as well as minimizing operating costs and risks to people and the environment. Operational indicators of a naval power plant show its reliability, possibility of overloading main propulsion engines, ship's maneuverability, time between overhauls (TBO), etc. Energy-related indicators on the other hand, e.g. efficiency, individual fuel consumption, power and torque determine the ship's speed through the water, its range, etc. $[1-5,9$, 12-14, 16].

Current exploitation systems mostly utilize strategies based on technical condition and overall operating costs. Decisions regarding exploitation in such systems require ongoing assessment of the technical condition of an object in use. Therefore, questions whether an object is functioning properly and what is the forecast for its further operational span are constantly valid. In cases of damage it is necessary to be able to locate it, and to identify the cause. For this purpose, systematic exploitation diagnostics are applied, including energy research. With the formulated measurement results at our disposal, it is possible to determine the characteristics of engines for further modeling and simulation purposes.

Operating characteristic can be best defined as a graphical or an analytical presentation of the relationship between the basic values which define the engine performance, as well as the working medium parameters measured in the specific engine cross-sections, and the values characterizing the working conditions of the engine mated with a specific load. These characteristics can be used for further modeling and simulation of the examined engines $[3-5,7,10,16]$. Based on modeling and simulation there is a possibility:

- determining whether an object is functioning (or may be functioning) properly - utility diagnoses obtained from the study of the functional properties of an object,
- determining a prognosis relating to the expected lifetime of an object - this is usually done by determining the probability of the correct operation in a given period of time,

- the possibility to locate each damage (obtaining sufficiently accurate operational diagnoses),

- determining the cause of a damage.

The paper identifies the object of the research study and presents the test results concerning the determination of the operating characteristics in steady states of the LM-2500 naval gas turbine being a component of the Oliver Hazard Perry class frigate. Preliminary tests were conducted in the ship's engine room when the ship was at sea. Operating characteristics of the engines were determined on the basis of the measurements recorded over the entire engine load range, from minimum to rated load.

\section{Study objective}

The objective of the study was to measure the operating parameters of the examined engine with regard to determining functional dependencies of its operating characteristics. These characteristics will be used in further energy modeling and simulations, as well as in diagnostics process this type of engine.

\section{Object and methods of study}

The LM 2500 naval gas turbines occur in a combined propulsion system (COGAG) installed in the 'Oliver Hazard Perry' missile frigates ORP "Pułaski" and ORP "Kościuszko". The propulsion system of this frigate consists of two LM 2500 naval gas turbines, reduction gear and shaft line with five-blade adjustable propeller. The total power of this propulsion system amounts to $30.000 \mathrm{~kW}$. The propulsion system enable the following operating modes [18]:

- operation of one engine on the starboard or portside,

- simultaneous operation of two engines on the starboard and portside.

In the near term, an another LM 2500 engine will come into operation together with a 661M patrol boat ORP "Ślązak".

LM 2500 naval gas turbine has dual-rotor design, with axial flow of the working mass. It consists of two main components: a gas generator and a power turbine. The gas 
generator consists of a 16-stage axial flow compressor, an annular type combustor equipped with 30 injectors and a two-stage high pressure turbine. Downstream of the gas generator there is a 6-stage power turbine which transmits torque to the line shaft through a reduction gear. The power turbine is connected with the gas generator in a thermo-gasdynamic manner [18]. LM-2500 naval gas turbine is shown in Fig. 1.

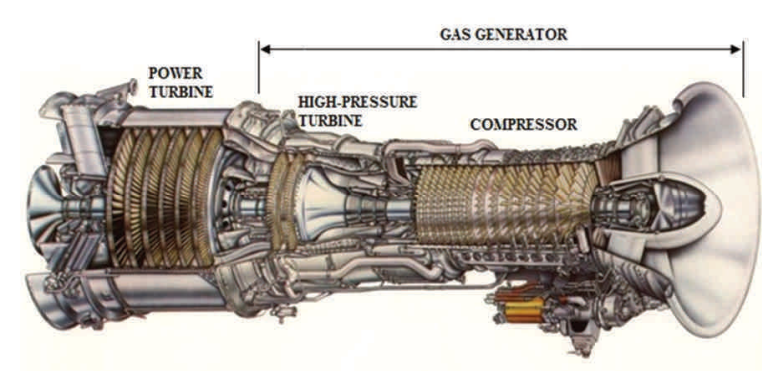

Fig. 1. Cross-section of LM-2500 naval gas turbine [18]

The energy research of naval gas turbines are conducted in order to:

- verify indications of marine control and measurement system,

- determine and assess changes concerning operating parameters of the engine during starting, idling, work with load and during stop (overrun),

- check the correct functioning of the automation system during start-up, while working with load and during stopping the engine,

- check the control parameters according to operational requirements, in particular during idling,

- analyse the operating characteristics of the engine,

- evaluate the fuel system in a steady state,

- assess the technical state of the flow part.

Table 1. Parameters of LM-2500 naval gas turbine measured during the study [18]

\begin{tabular}{|l|c|c|}
\hline $\begin{array}{l}\text { parameter } \\
\text { designation }\end{array}$ & measuring range & description of the parameter \\
\hline $\mathrm{n}_{\mathrm{GG}}$ & $0-12000 \mathrm{RPM}$ & gas generator speed \\
\hline $\mathrm{n}_{\mathrm{PT}}$ & $0-5000 \mathrm{RPM}$ & power turbine speed \\
\hline $\mathrm{p}_{1}$ & $0-16 \mathrm{psia}$ & gas generator inlet air pressure \\
\hline $\mathrm{T}_{1}$ & $-40-150^{\circ} \mathrm{F}$ & $\begin{array}{c}\text { gas generator inlet air } \\
\text { temperature }\end{array}$ \\
\hline $\mathrm{p}_{\mathrm{CDP}}$ & $0-300 \mathrm{psig}$ & $\begin{array}{c}\text { gas generator compressor } \\
\text { discharge air pressure }\end{array}$ \\
\hline$\pi$ & $0-20$ & compressor pressure ratio \\
\hline $\mathrm{p}_{4.1}$ & $0-75 \mathrm{psia}$ & $\begin{array}{c}\text { power turbine inlet exhaust gas } \\
\text { pressure }\end{array}$ \\
\hline $\mathrm{T}_{4.1}$ & $0-2000^{\circ} \mathrm{F}$ & $\begin{array}{l}\text { power turbine inlet exhaust gas } \\
\text { temperature }\end{array}$ \\
\hline $\mathrm{p}_{\text {fuel }}$ & $0-1500 \mathrm{psig}$ & fuel manifold pressure \\
\hline $\mathrm{M}$ & $0-35000 \mathrm{ft} \cdot 1 \mathrm{bf}$ & torque output \\
\hline $\mathrm{P}$ & $0-25000 \mathrm{HP}$ & power output \\
\hline
\end{tabular}

The study were conducted in motion onboard a two frigates (four engines together), for steady load states, determined on the basis of the gas generator speed over the entire load range of the engine, from minimum to rated load. Engines were loaded in accordance with the propulsion system control program. This program - depending on the preset speed of the ship - selects the optimum setting of propeller pitch and fuel flow and controls the angle of attack of six stages of Variable Stator Vanes (VSV) in the engines' axial compressor. Parameters measured during the study are presented in Table 1.

The schematic diagram of LM-2500 naval gas turbine and the legend describing location of the measured parameters is shown in Fig. 2.

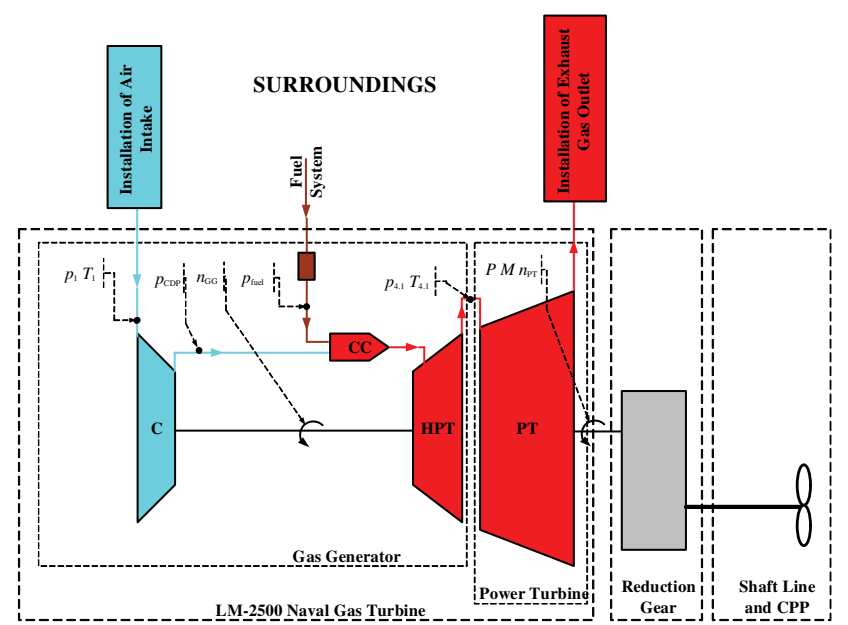

Fig. 2. The schematic diagram of LM-2500 naval gas turbine and the legend describing location of the measured parameters

The parameters were measured simultaneously for both engines, on the load of both engines simultaneous and balanced. The measurements were made using the portable measuring-recording system, Multichannel Recorder type 908416161C and additionally, the operating parameter values were read and recorded from digital displays on the main control panel in the engine control room. The measurements were made for 60 seconds at specific load settings, with the sampling rate of $2 \mathrm{~Hz}$, and then averaged. Measurements were preceded by the calibration of individual measuring circuits including the assessment of their uncertainties. The measuring-recording system during the measurement is shown in Fig. 3.

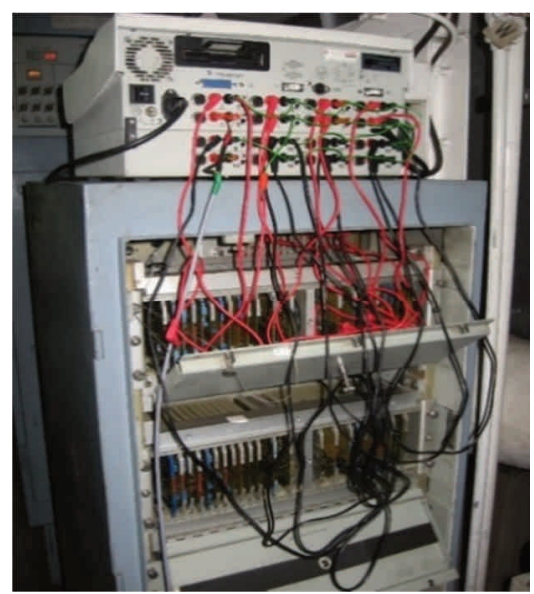

Fig. 3. The measuring-recording system during the measurement

Parameters were recorded in units of the imperial system of measurement (United States Customary System Units), since in such units measure the measuring instru- 
ments on the ship. All registered parameter values are dependent on weather conditions during the study. Therefore, these parameters were reduced to standard reference state using the formulas described in Table 2. Standard reference state are determined by standard pressure 1 atm (101 325 $\mathrm{Pa}$ ) and standard temperature 288.15 K [17]. Additionally, ambient pressure was taken into account when determin ing absolute pressures.

Table 2. Conversion formulas used to reduce the value of the measured parameters to standard reference state (indexes: $\mathrm{R}$ - reduced, $\mathrm{M}$ - measured, 0 - ambient) [17]

\begin{tabular}{|l|c|}
\hline Parameter & Conversion formula \\
\hline Power & $\mathrm{P}_{\mathrm{R}}=\mathrm{P}_{\mathrm{M}} \cdot \frac{101325}{\mathrm{p}_{0}} \cdot \sqrt{\frac{288.15}{\mathrm{~T}_{0}}}$ \\
\hline Sprque & $\mathrm{M}_{\mathrm{R}}=\mathrm{M}_{\mathrm{M}} \cdot \frac{101325}{\mathrm{p}_{0}} \cdot \sqrt{\frac{288.15}{\mathrm{~T}_{0}}}$ \\
\hline Mass Flow Rate & $\mathrm{n}_{\mathrm{R}}=\mathrm{n}_{\mathrm{M}} \cdot \sqrt{\frac{288.15}{\mathrm{~T}_{0}}}$ \\
\hline Temperature & $\dot{\mathrm{m}}_{\mathrm{R}}=\dot{\mathrm{m}}_{\mathrm{M}} \cdot \frac{101325}{\mathrm{p}_{0}} \cdot \sqrt{\frac{\mathrm{T}_{0}}{288.15}}$ \\
\hline Pressure (air, exhaust gas) & $\mathrm{T}_{\mathrm{R}}=\mathrm{T}_{\mathrm{M}} \cdot \frac{288.15}{\mathrm{~T}_{0}}$ \\
\hline Hourly Fuel Consumption & $\mathrm{p}_{\mathrm{R}}=\mathrm{p}_{\mathrm{M}} \cdot \frac{101325}{\mathrm{p}_{0}}$ \\
\hline Fuel Pressure & $\mathrm{B}_{\mathrm{h}_{\mathrm{R}}}=\mathrm{B}_{\mathrm{h}_{\mathrm{M}}} \cdot \frac{101325}{\mathrm{p}_{0}} \cdot \sqrt{\frac{288.15}{\mathrm{~T}_{0}}}$ \\
\hline
\end{tabular}

\section{Results obtained}

\subsection{Start-up and stoppage characteristics of the engine and idling}

The start-up is a transient process, consisting of a series of dynamic thermal-gaseous processes running simultaneously in all turbine engine fluid-flow machines, aimed at transferring the engine from the idle state to the idle running. In other words, the start-up is the transition from the rotary rim resting state to idle speed. One of the most important requirements for turbine engine starting systems is the automatic, reliable and trouble-free start-up in all weather conditions $[10,18]$. Start-up characteristics depend on corresponding adjustments made in the relevant engine and on its technical condition. Therefore, they are individual for every engine within an engine group of a specific type.

Based on the characteristics of the starting and stopping processes of the engine, conclusions may be drawn about correct functioning of the automatic engine start control system, including:

- evaluation of various stages of start-up and correct operation of equipment and installations involved in the start-up process,

- observe the correctness of operation of fuel equipment,

- verify the achievement of required values of the start control parameters in a determined time,

- observe the correctness of the technical condition of the engine bearings,

- carry out the necessary regulations in this regard.
Based on the engine operating parameters recorded in idle running, conclusions may be drawn about the correctness of engine adjustment, as well as the correctness of operation of the fuel equipment. Analysis of the research results is carried out by comparing the measured parameter values with the control parameter values, contained in the operational documentation of the examined engine.

Examples of start-up and stoppage (coasting) characteristics of an engine, recorded during the energetic state parameters measurements of LM 2500 naval gas turbine are presented in Fig. 4-5. Designations of individual control parameters are in accordance with the engine operating parameters contained in Table 1.

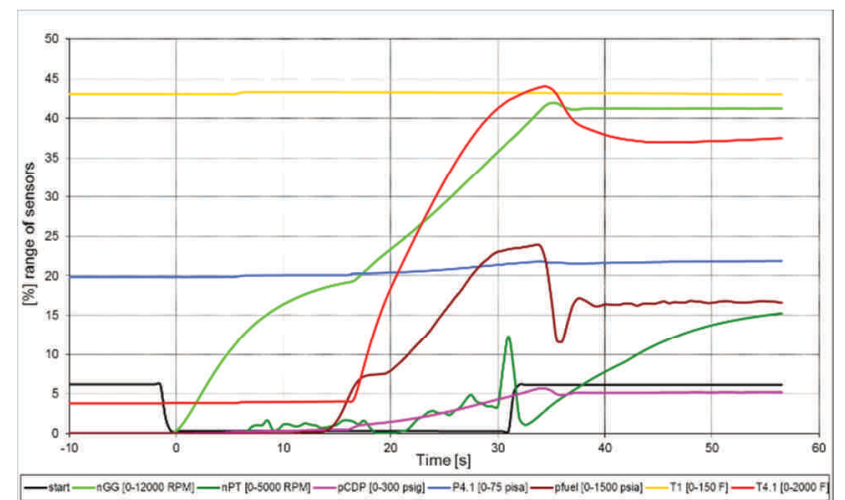

Fig. 4. Course of the relative values of control parameters for start-up of a naval gas turbine LM 2500

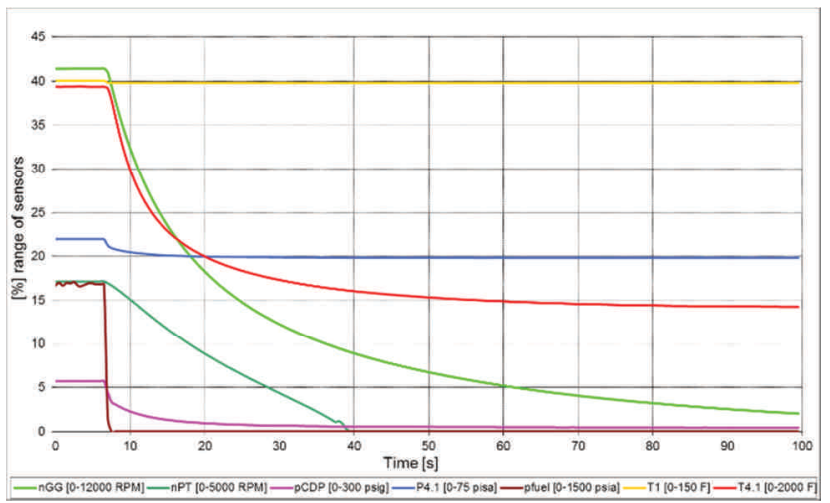

Fig. 5. Course of the relative values of control parameters for the stopping (coasting) of a naval gas turbine LM 2500

\subsection{Operating characteristics}

Operating characteristics present functional dependencies of between engine operating parameters and the gas generator speed, while maintaining the power turbine speed resulting from its mating to a load being a controllable pitch propeller (CPP). Operating characteristics of the examined engine were determined on the basis of the measurement results from the four engines.

Subsequently, the characteristics obtained were analyzed to determine approximating dependencies. Statistical analysis was used to that end. Statistical analysis is the method of processing data (results of measurements performed according to an assumed program of tests) in order to find regularities in the examined phenomena and to interpret them using the methods employed in mathematical statistics. This facilitates establishing the mathematical function of the examined 
object, which may also constitute its mathematical model. The results obtained by means of statistical analysis are the basis for obtaining useful information concerning the examined object and for drawing conclusions from the conducted research. The most common measure of relating the obtained function of the examined object to the measurement results is the coefficient of determination $\mathrm{R}^{2}$, the average approximation error $\sigma(\mathrm{y})$ (also known as standard deviation) and relative error $\sigma[6,11,15]$. In addition to the statistical analysis, a substantive analysis of the test results was also carried out. That analysis concerned particularly the validation of the mathematical model obtained for its compliance with the physical phenomena occurring within the relevant examined engine, taking into consideration both theoretical foundations and the principles of operating the engine. In order to approximate the rotational characteristics, least-squares method (LSM) was used, making use of a third-degree polynomials $[11,15]$ :

$$
\mathrm{y}=\mathrm{b}_{0}+\mathrm{b}_{1} \cdot \mathrm{n}_{\mathrm{GG}}+\mathrm{b}_{2} \cdot \mathrm{n}_{\mathrm{GG}}^{2}+\mathrm{b}_{3} \cdot \mathrm{n}_{\mathrm{GG}}^{3}
$$

for which the coefficient of determination $\mathrm{R}^{2}$ was the largest $[11,15]$. Approximated operating characteristics and the results of the measurements examined engine, recorded for steady-state operation, in relation to gas generator speed $\mathrm{n}_{\mathrm{GG}}$ are presented in Figs $6-15$. The results of statistical analysis of approximated operating characteristics are shown in Table 3.

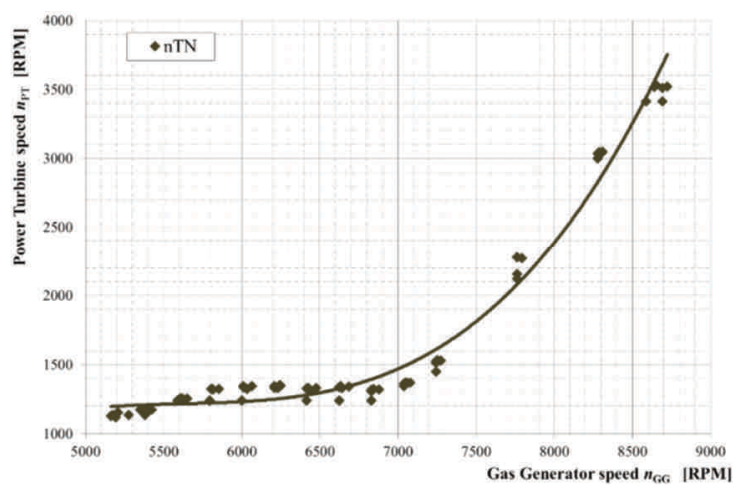

Fig. 6. Approximated function and the results of the measurements of power turbine speed $n_{P T}$, recorded for steady-state operation of LM-2500 engine, in relation to gas generator speed $\mathrm{n}_{\mathrm{GG}}$

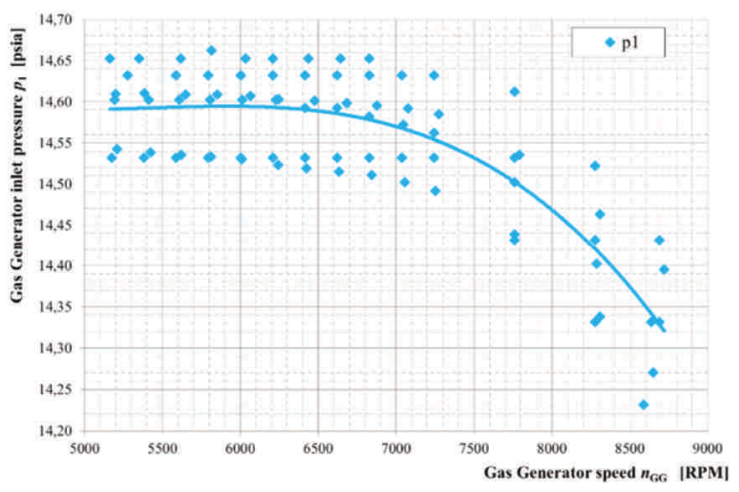

Fig. 7. Approximated function and the results of the measurements of gas generator inlet air pressure $\mathrm{p}_{1}$, recorded for steady-state operation of LM2500 engine, in relation to gas generator speed $\mathrm{n}_{\mathrm{GC}}$

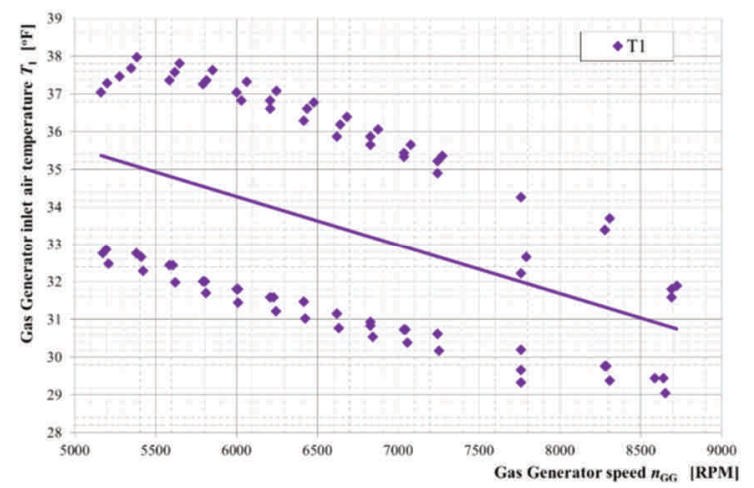

Fig. 8. Approximated function and the results of the measurements of gas generator inlet air temperature $\mathrm{T}_{1}$, recorded for steady-state operation of $\mathrm{LM}-2500$ engine, in relation to gas generator speed $\mathrm{n}_{\mathrm{GG}}$

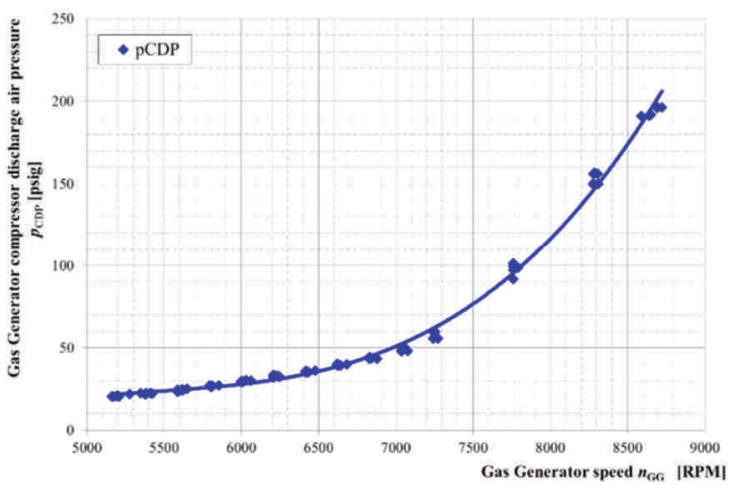

Fig. 9. Approximated function and the results of the measurements of gas generator compressor discharge air pressure $\mathrm{p}_{\mathrm{CDP}}$, recorded for steady-state operation of LM-2500 engine, in relation to gas generator speed $\mathrm{n}_{\mathrm{GG}}$

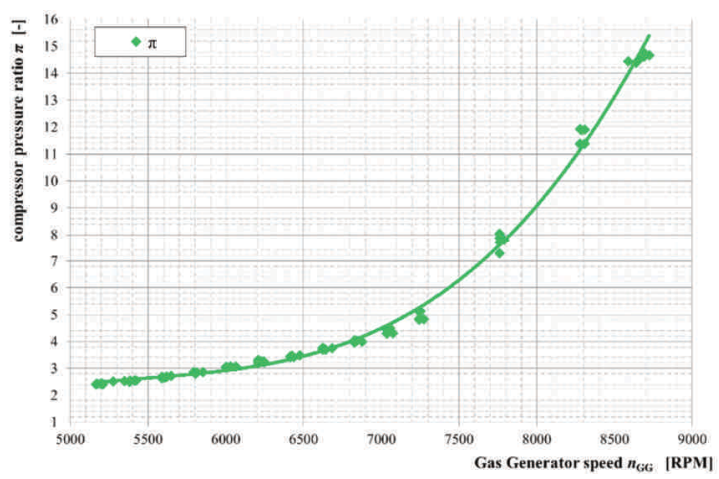

Fig. 10. Approximated function and the results of the measurements of compressor pressure ratio $\pi$, recorded for steady-state operation of LM2500 engine, in relation to gas generator speed $\mathrm{n}_{\mathrm{GG}}$

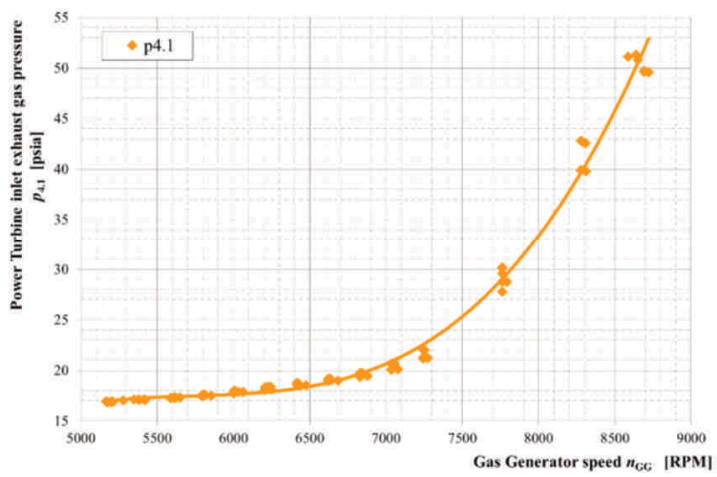

Fig. 11. Approximated function and the results of the measurements of power turbine inlet exhaust gas pressure $\mathrm{p}_{4.1}$, recorded for steady-state operation of LM-2500 engine, in relation to gas generator speed $\mathrm{n}_{\mathrm{GG}}$ 


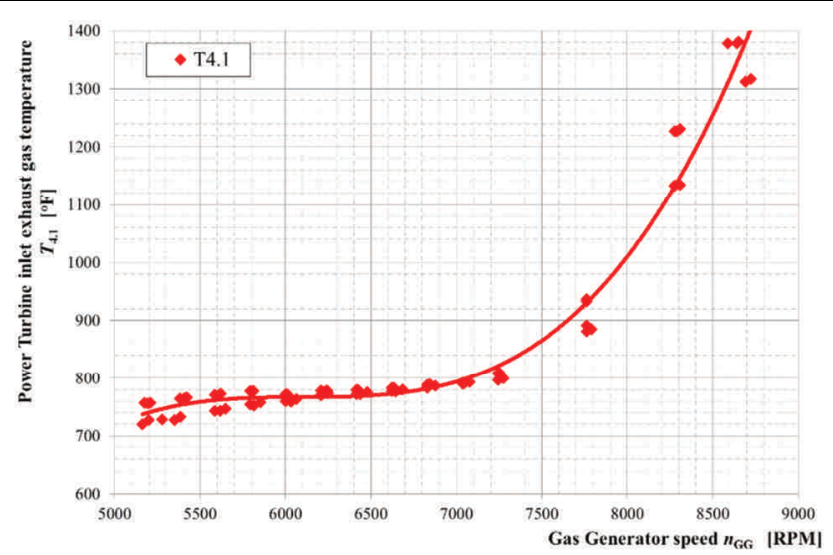

Fig. 12. Approximated function and the results of the measurements of power turbine inlet exhaust gas temperature $\mathrm{T}_{4.1}$, recorded for steady-state operation of LM-2500 engine, in relation to gas generator speed $\mathrm{n}_{\mathrm{GG}}$

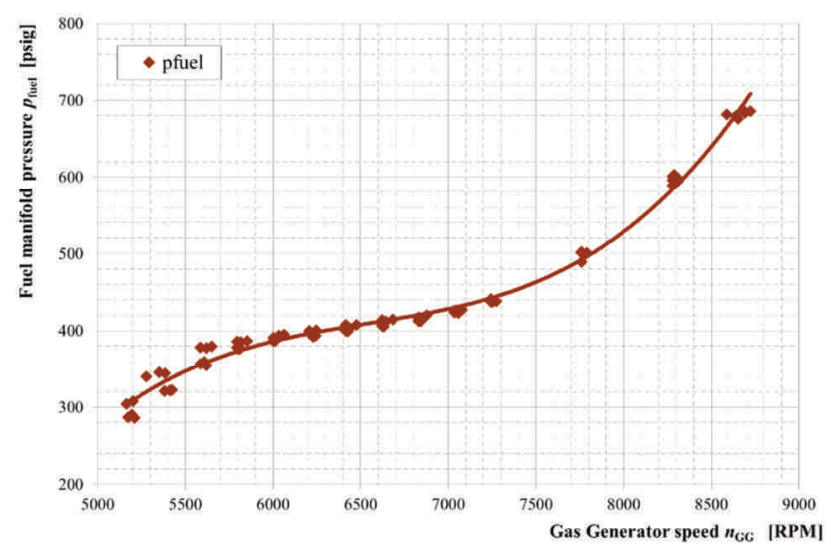

Fig. 13. Approximated function and the results of the measurements fuel manifold pressure $\mathrm{p}_{\text {fuel }}$, recorded for steady-state operation of LM-2500 engine, in relation to gas generator speed $\mathrm{n}_{\mathrm{GG}}$

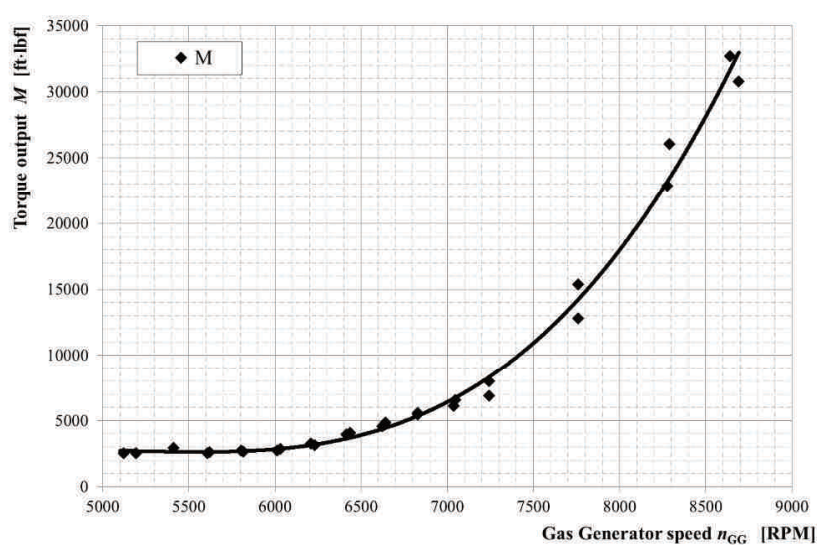

Fig. 14. Approximated function and the results of the measurements of torque output M, recorded for steady-state operation of LM-2500 engine, in relation to gas generator speed $\mathrm{n}_{\mathrm{GG}}$

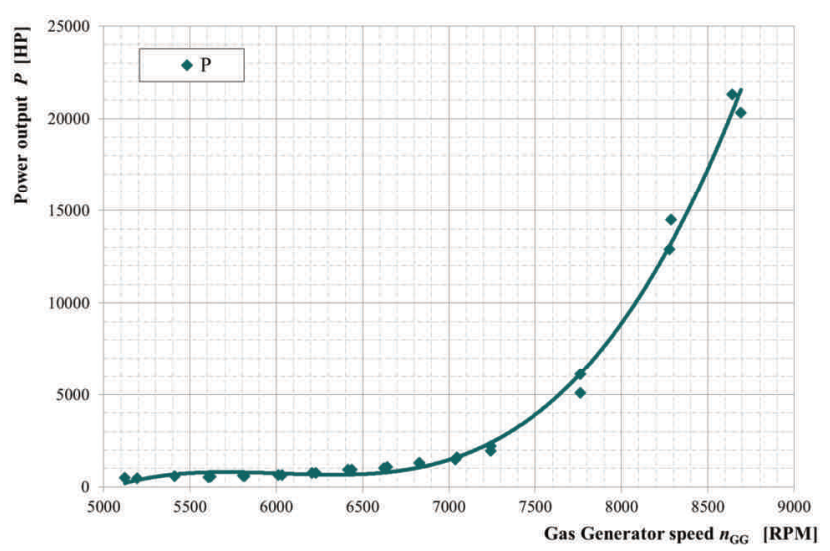

Fig. 15. Approximated function and the results of the measurements of power output $\mathrm{P}$, recorded for steady-state operation of LM-2500 engine, in relation to gas generator speed $\mathrm{n}_{\mathrm{GG}}$

Table 3. The results of statistical analysis of approximated operating characteristics

\begin{tabular}{|c|c|c|c|c|c|c|c|}
\hline \multirow{2}{*}{$\begin{array}{c}\text { function } \\
\mathrm{y}=\mathrm{f}\left(\mathrm{n}_{\mathrm{GG}}\right)\end{array}$} & \multicolumn{3}{|c|}{ coefficients of the polynomial equation } & \multirow{2}{*}{$\mathrm{R}^{2}$} & \multirow{2}{*}{$\sigma(\mathrm{y})$} & \multirow{2}{*}{$\sigma[\%]$} \\
\cline { 2 - 7 } & $\mathrm{b}_{0}$ & $\mathrm{~b}_{1}$ & $\mathrm{~b}_{2}$ & $\mathrm{~b}_{3}$ & & & \\
\hline $\mathrm{n}_{\mathrm{PT}}=\mathrm{f}\left(\mathrm{n}_{\mathrm{GG}}\right)$ & -13664.92 & 7.88 & $-1.39 \cdot 10^{-3}$ & $8.26 \cdot 10^{-8}$ & 0.9885 & 108 & 2.7 \\
\hline $\mathrm{p}_{1}=\mathrm{f}\left(\mathrm{n}_{\mathrm{GG}}\right)$ & 15.83 & $-6.99 \cdot 10^{-4}$ & $1.30 \cdot 10^{-7}$ & $-8.04 \cdot 10^{-12}$ & 0.8234 & 0.05 & 0.4 \\
\hline $\mathrm{T}_{1}=\mathrm{f}\left(\mathrm{n}_{\mathrm{GG}}\right)$ & 42.08 & $1.30 \cdot 10^{-3}$ & - & - & 0.4788 & 2.4 & 6.1 \\
\hline $\mathrm{p}_{\mathrm{CDP}}=\mathrm{f}\left(\mathrm{n}_{\mathrm{GG}}\right)$ & -753.64 & $4.15 \cdot 10^{-1}$ & $-7.49 \cdot 10^{-5}$ & $4.58 \cdot 10^{-9}$ & 0.9980 & 3.28 & 1.3 \\
\hline$\pi=\mathrm{f}\left(\mathrm{n}_{\mathrm{GG}}\right)$ & -54.58 & $3.04 \cdot 10^{-2}$ & $-5.45 \cdot 10^{-6}$ & $3.31 \cdot 10^{-10}$ & 0.9999 & 0.24 & 1.3 \\
\hline $\mathrm{p}_{4.1}=\mathrm{f}\left(\mathrm{n}_{\mathrm{GG}}\right)$ & -227.46 & $1.27 \cdot 10^{-1}$ & $-2.21 \cdot 10^{-5}$ & $1.28 \cdot 10^{-9}$ & 0.9957 & 0.93 & 1.7 \\
\hline $\mathrm{T}_{4.1}=\mathrm{f}\left(\mathrm{n}_{\mathrm{GG}}\right)$ & -7157.88 & 3.90 & $-6.39 \cdot 10^{-4}$ & $3.49 \cdot 10^{-8}$ & 0.9877 & 27.8 & 1.9 \\
\hline $\mathrm{p}_{\text {fuel }}=\mathrm{f}\left(\mathrm{n}_{\mathrm{GG}}\right)$ & -5756.18 & 2.75 & $-4.15 \cdot 10^{-4}$ & $2.11 \cdot 10^{-8}$ & 0.9952 & 9.6 & 2.2 \\
\hline $\mathrm{M}=\mathrm{f}\left(\mathrm{n}_{\mathrm{GG}}\right)$ & -102277.48 & 60.84 & $-1.17 \cdot 10^{-2}$ & $7.47 \cdot 10^{-7}$ & 0.9954 & 868 & 1.7 \\
\hline $\mathrm{P}=\mathrm{f}\left(\mathrm{n}_{\mathrm{GG}}\right)$ & -246467.07 & 123.85 & $-2.06 \cdot 10^{-2}$ & $1.14 \cdot 10^{-6}$ & 0.9968 & 485 & 1.9 \\
\hline
\end{tabular}

Analyses of the functions describing operating characteristics of the examined engine show that variation range of the studied operating parameters is in compliance with the specification given by the ship's documentation. The operating characteristic graphs point out to the nonlinear character of the relationships between operating parameters and the engine load. The non-linear character of the said relationships results from the fact that the power turbine is mated to a controllable pitch propeller (CPP). Only the characteristic of the gas generator inlet air temperature $T_{1}$ is linear. It is also noticeable that the curves are linear in the range from minimum load to the load at which maximum propeller pitch angle is reached. Maximum propeller pitch angle occurs at the gas generator speed of approximately 7000 RPM. The characteristics also show that a significant increase in engine power output occurs after reaching the maximum propeller pitch angle, when the power turbine is mated with the propeller set at its maximum steady pitch angle. Upon reaching the maximum propeller pitch angle, the engine delivers an output of approximately $2000 \mathrm{HP}$, with a maximum power output of $25000 \mathrm{HP}$.

\subsection{Acceleration and deceleration characteristics}

The process of exploitation of naval gas turbines also requires the knowledge of their characteristics in the process of acceleration and deceleration of the engine. These 
characteristics represent the change dynamics of various engine parameters at the time of increasing or decreasing a load. On this basis, it is possible to evaluate the prevalence of unstable ranges of engine operation, which may lead to the pumping. The course of changes in an LM 2500 engine selected operating parameters during acceleration and deceleration is presented in Fig. 16-17. Designation of individual parameters is in accordance with the engine operating parameters contained in Table 1.

\section{Conclusions}

The determined functional dependencies of the LM2500 naval gas turbine will facilitate analytical determination of engine operating parameters on the basis of gas generator speed, for any ambient parameters. The values of engine operating parameters determined on the basis of the aforementioned dependencies are approximate but their accuracy is sufficient for engineering applications to meet the need of further research concerning this type of engine. In particular, research in the aspect of energy modeling and simulations.

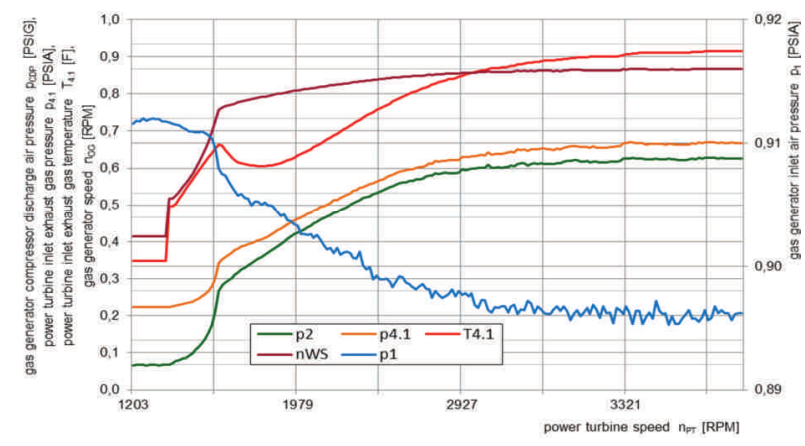

Fig. 16. Changes of LM 2500 engine operating parameters depending on the power turbine speed $n_{\mathrm{PT}}$ during acceleration

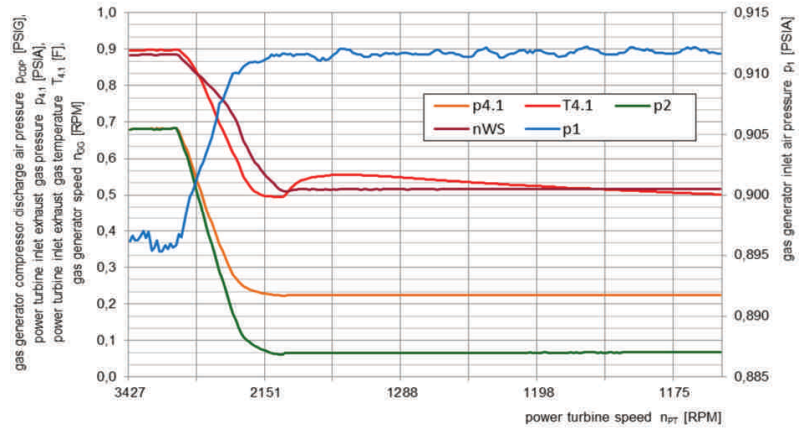

Fig. 17. Changes of LM 2500 engine operating parameters depending on the power turbine speed $n_{\mathrm{PT}}$ during deceleration

The possibility of determining engine operating characteristics facilitates their use in the process of diagnostics in its broad sense. Owing to that, there is a possibility of conscious operation of equipment according to its technical condition. Observing the trends present in the changes of the operating characteristics and selected diagnostic symptoms facilitates obtaining data which may be used in the decision-making process related to equipment operation in order to ensure naval combat readiness, as well as to maintenance, adjustment or replacement of engine components and finally, to repairs. That data may also be used to design new engines or upgrade the existing.

Knowledge and experience related to operating characteristics are also used in the process of education and training people responsible for operating of such engines. This is particularly important because incorrect operation often leads to serious failures, which affect the combat readiness of the ship, and also generate large and unexpected costs in the process of ship's operation.

\section{Nomenclature}

COGAG combined gas turbine and gas turbine

CPP controllable pitch propeller

ime between overhauls variable stator vanes

\section{Bibliography}

[1] FLYNN, D. (eds.)., Thermal power plants -simulation and control. The Institution of Electrical Engineers. London 2000.

[2] CUI, J.G., ZHANG, L., WANG, G.H. et al. Fault prediction method of the marine gas turbine based on neural networkMarkov. Applied Mechanics and Materials. 2014, 538, 171174.

[3] GAO, J.H., HUANG, Y.Y. Effect of ambient temperature on three-shaft gas turbine performance under different control strategy. Advanced Materials Research. 2012, 424-425, 276280.

[4] KIM, K.H. Effects of water and steam injection on thermodynamic performance of gas-turbine systems. Applied Mechanics and Materials. 2011, 110-116, 2109-2116.

[5] CAO, L., LI, S.Y., WANG, Z.T. The study of marine gas turbine power system simulation software development. Applied Mechanics and Materials. 2013, 300-301, 166-171.
[6] MAŃCZAK, K. Design of experiments. WNT. Warszawa 1976.

[7] BASHA, M., SHAAHID, S.M., AL-HADHRAMI, L. Impact of gas turbine frame size on efficiency of gas turbine power plants. Applied Mechanics and Materials. 2014, 492, 447-452.

[8] MEYER, R.T., DECARLO, R.A., PEKAREK, S., DOKTORCIK, C. Gas turbine engine behavioral modeling. School of Electrical and Computer Engineering, Purdue University. West Lafayette, IN 47907-1288, USA 2014.

[9] FUKUDA, M., HARADA, H., YOKOKAWA, T., KITASHIMA, T. Virtual jet engine system. Materials Science Forum. 2010, 638-642, 2239-2244.

[10] POJAWA, B. The investigation of turbine engine in aspect of output torque control. Solid State Phenomena. 2012, 180, 339-348.

[11] POLAŃSKI, Z. Design of experiments in technique. $P W N$. Warszawa 1984. 
[12] WANG, Q., MA, Y.F., HU, X.M. Research on $\mathrm{NO}_{\mathrm{x}}$ concentration field distribution of a turbo-jet engine emissions. $A d$ vanced Materials Research. 2013, 732-733, 46-51.

[13] MARTINS, R.F., BRANCO, C.M., GONÇALVES-COELHO, A.M., GOMES, E.C. Failure mechanisms on exhaust systems of naval gas turbines. Materials Science Forum. 2008, 587588, 946-950.

[14] ZHU, R., REN, J.X., LI, F.Q. et al. Thermal and stress field analysis in heavy-duty gas turbine exhaust system. Advanced Materials Research. 2012, 516-517, 688-691.

[15] TAYLOR, J.R. Introduction to analysis of measuring error. PWN. Warszawa 1999.

Bogdan Pojawa, DEng. - Mechanical and Electrical Engineering Faculty at Polish Naval Academy in Gdynia.

e-mail:B.Pojawa@amw.gdynia.pl
[16] QUAN, X.H., QUAN, J.J., HE, H. Modeling and simulation of a certain warship diesel engine based on AMESim. Applied Mechanics and Materials. 2014, 496-500, 760-763.

[17] CENGEL, Y.A., BOLES, M.A. Termodynamics fifth edition in SI units. McGraw-Hill Higher Education. New York 2006.

[18] Technical, manual and organizational level maintenance LM-2500 propulsion gas turbine module of propulsion system of Oliver Hazard Perry class frigate FFG-9. Marine and Industrial Engines and Services Division, General Electric Company, Ohio 2003.

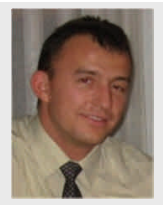

